\title{
The spatial patterning of alcohol outlets in post-disaster Christchurch, New Zealand: \\ Practical and policy implications
}

\author{
Gregory Dennis Breetzke ${ }^{\mathrm{a}^{*}}$ and Amber L. Pearson ${ }^{\mathrm{b}}$ \\ ${ }^{\text {a }}$ Department of Geography, Geoinformatics and Meteorology, University of Pretoria, Pretoria, South Africa; \\ ${ }^{\mathrm{b}}$ Department of Geography, Environment \& Spatial Sciences, Michigan State University, East Lansing, MI, US
}

*Correspondence to: Gregory Dennis Breetzke, greg.breetzke@up.ac.za

\begin{abstract}
Natural disasters greatly impact the environment of affected societies with often unknown consequences. In this study we examine the impact that the Canterbury Earthquakes of 2010/2011 had on the distribution of alcohol outlets in Christchurch, New Zealand. Specifically, we compare the distribution of both on-site and off-site alcohol outlets pre(December 2009) and post-earthquake (December 2014) and use spatial regression models to identify whether any neighbourhood-level factors predict the observed redistributions. Overall, the number of alcohol outlets decreased by almost 13 percent after the Canterbury Earthquakes. However, we found a moderate increase in the clustering of both outlet types of outlets in the post-quake period. Increases in rates of both on-site and off-site alcohol outlets in neighbourhoods were positively associated with the percentage of residents who resided in their neighbourhood $<5$ years and with neighbourhood crime rate change, while negative associations were found with percentage population aged between 15 and 29 years. The practical and policy implications of a redistribution of alcohol outlets are outlined providing a tangible link between empirical research and practice in an urban environment plagued with post-disaster spatial and social uncertainties.
\end{abstract}

Keywords: Alcohol outlets; natural disaster; earthquake; spatial regression; Christchurch 


\section{Introduction}

A plethora of studies have investigated the spatial patterning of alcohol outlets. The results across this broad swathe of literature covering numerous geographic locales are that alcohol outlets generally cluster in space (see Han \& Gorman, 2014; Zhang et al., 2015), and are disproportionately located in minority (see Gorman \& Speer, 1997; LaVeist \& Wallace Jr., 2000) and/or in lower income neighbourhoods (see Bluthenthal et al., 2008; Schneider \& Gruber, 2014). Echoing the majority of findings from other countries, New Zealand studies have also found alcohol outlets to be spatially clustered (Pearce et al., 2008; Hay et al., 2009), and to be predominantly located in minority Māori and/or more deprived neighbourhoods (see Hay et al., 2009; Vinther-Larsen et al., 2013) although this has found to vary by type of outlet (Cameron et al., 2012).

The consequences of the spatial clustering of alcohol outlets are also well-known, particularly for crime and health. For example, a large number of studies have found direct and significant relationships between alcohol availability and crime both internationally and in New Zealand (see Gorman et al., 2001; Cameron et al., 2016). Studies have also found direct relationships between alcohol availability and other health-related behaviours and outcomes such as suicide (Escobedo \& Oritz, 2002), sexually transmitted diseases (Cohen et al., 2006), motor vehicle crashes (Treno et al., 2011) and hazardous drinking (Stockwell et al., 2009).

While the causes and consequences of the spatial patterning of alcohol outlets are generally well-known, studies examining the spatial location choice of outlets in a postdisaster setting are less forthcoming. In fact, we are unaware of any previous research that has examined how the spatial distribution of alcohol outlets change in a city or region in the aftermath of a natural disaster. Such exploration is important from both an urban planning and population health perspective. In terms of the former, natural disasters greatly impact the 
spatial design and configuration of cities. Notwithstanding the catastrophic infrastructural damage that afflicts the built environment, the impacts on the natural environment (i.e., liquefaction, biodiversity, water quality) can greatly hinder the rebuilding process. In terms of the latter, natural disasters greatly impact the affected population and have been shown to lead not only to a change in attitudes to life (see Burke et al., 1982; Mearidy-Bell, 2013) and mental health of residents (Ursano et al., 2009), but also to an increase in risk-taking behaviours (Cameron \& Shah, 2015), including increased harmful alcohol consumption (Schroeder \& Polusny, 2004) and alcohol-related harm (Rohrbach et al., 2009). The causal pathways underlying these latter relationships are myriad but are generally thought to be related to the psychosocial stressors experienced by residents in the immediate aftermath of such an event. Post-disaster stressors such as relocation and the loss of social and capital resources may magnify the immediate distress induced by a disaster and can also lead to increased post-disaster alcohol use and abuse.

In this study, we investigated how the spatial distribution of both on- and off-site alcohol outlets in Christchurch changed in the wake of two major earthquakes that struck the Canterbury region of the south island of New Zealand in September 2010 and February 2011. Specifically, we compare the 2009 (pre-earthquake) distribution of on- and off-site alcohol outlets with the 2014 (post-earthquake) outlet distributions. We investigate whether there was a change in the spatial clustering of outlets, as well as, use spatial regression models to identify whether any neighbourhood-level socio-demographic factors can predict the redistribution of outlets. Finally, we were specifically interested in examining whether any spatial relationship exists between the changing distribution of both alcohol outlets and neighbourhood crime in a post-disaster setting and thus added this variable to the above model. Prior research has shown how the availability of alcohol, promoted through the physical location of outlets is recognised as an important contextual influence on both levels 
of neighbourhood violence and other alcohol-related harms (see Ayuka et al., 2014; Conrow et al., 2015). The results of this study can reveal what neighbourhood-level factors predict this redistribution as well as allow us to speculate on the effects this redistribution could have on the population health of the city. The rest of our paper proceeds accordingly. We first provide a brief overview of the Canterbury Earthquake sequence and briefly examine its effects on the alcohol industry in Christchurch; we then outline our data and describe our methods before providing and discussing the results. The practical and policy implications of our findings conclude.

\section{The Canterbury Earthquakes}

The first Canterbury Earthquake struck the south island of New Zealand at 0435a.m on $4^{\text {th }}$ September 2010 and was centered in Darfield roughly 40 kilometres outside the main city in the Canterbury region, Christchurch. The earthquake registered a moment magnitude $(M w)$ of 7.1 and resulted in widespread infrastructural damage to the region. The second Canterbury Earthquake ( $M w$ of 6.3 ) struck at 1251 p.m. on the $22^{\text {nd }}$ February 2011 and caused even greater damage to the region as it was centered closer to the Christchurch city centre ${ }^{1}$. Significantly, the latter event resulted in widespread injuries and the death of 185 people. The physical effects of the Canterbury Earthquakes were significant. The lateral and vertical movement of the Earthquakes resulted in significant building damage throughout the Canterbury region. Damage varied considerably from the superficial cracking of paint, to extreme structural damage, and in rare cases, the collapse of buildings. These combined earthquake events were the costliest disaster ever to occur in New Zealand and resulted in damage estimated to reach NZ\$40 billion or roughly $20 \%$ of the country's Gross Domestic Product (GDP) (New Zealand Treasury, 2013). In the immediate aftermath of these events, a

\footnotetext{
${ }^{1}$ From this point onwards these collective events area referred to as the Canterbury Earthquakes.
} 
cordon was placed around the central business district (CBD) of Christchurch and extensive structural assessments undertaken within the cordoned off area as well as across the city as a whole to ascertain the level of damage sustained. Within the CBD, $47 \%$ of buildings were assessed to be unsafe or required restricted access (Kam et al., 2011) while across the city over 150,000 houses (around three quarters of Christchurch's housing stock) sustained some damage from the earthquakes, and of these around a fifth exceeded NZ\$100,000 in estimated damage (Parker \& Steenkamp, 2012). Over 60\% of the roughly 6000 businesses located in the Christchurch CBD - employing almost $30 \%$ of the Christchurch workforce - were forced to close at least temporarily (Stevenson et al., 2012). This included a total of 297 alcohol outlets, or approximately $37 \%$ of all alcohol outlets located in Christchurch.

In fact, alcohol outlets in Christchurch experienced significant upheaval in the aftermath of the Canterbury Earthquakes. Of the alcohol outlets operating in Christchurch before the earthquake only 56 percent were operating by the end of 2014; many closed down permanently while others re-located. The city had a pre-quake peak of 747 actively trading licenses in December 2009 which plunged to a low of 477 in February 2011 immediately following the second earthquake before slowly climbing up to 644 in December 2014.

Since February 2011, Christchurch has been in a constant and ever-changing state of rebuild and recovery. Over 1200 buildings have been demolished, mostly in the CBD and in a region of Christchurch known as the Residential Red Zone (Canterbury Earthquake Recovery Authority (CERA), 2015). This is a non-continuous zone of land defined throughout residential areas in Christchurch where earthquake damage was most severe, and where a substantial numbers of properties were deemed unsafe for future habitation. The rebuild of Christchurch is governed by the Christchurch Central Recovery Plan (CCRP) which provides a spatial framework for the rebuilt city by setting out the locations of key urban anchor 
projects, and also links CERA $^{2}$ and the central government in a leadership role in collaboration with the Christchurch City Council for land acquisition, development proposal decisions, and reconstruction management (Johnson \& Mamula-Seadon, 2014). One key objective of the CCRP is to investigate ways to bring people, business and investment back to the central city. While demolitions in the central city have outnumbered rebuilds by four to one since the earthquakes (see CERA, 2015) a number of businesses in particular have relocated to the central city and immediate surroundings. Among those businesses returning are a plethora of entertainment establishments and other businesses that are licensed to serve and sell alcohol.

\section{Material and methods}

\section{Study area}

The study area for this research is the city of Christchurch located in the south island of New Zealand. The unit of analysis employed is the census area unit (CAU). A CAU is the second smallest unit of dissemination of census data in New Zealand and usefully approximates a neighbourhood, with each CAU representing approximately two and half thousand people. In 2013, Christchurch had a total residential population of roughly 340,000 located in 119 CAUs.

\section{Dependent variable}

The alcohol outlet data used in this research was created specifically for this study. Usually alcohol outlet data in New Zealand can be obtained from the Alcohol Regulatory and Licensing Authority (ARLA) which has statutory authority to collect licensing information. However, in a post-disaster setting, the reliability and validity of this information can be

\footnotetext{
${ }^{2}$ CERA is a public service department of the New Zealand government formed in 2011 and charged with assessing damage and coordinating the rebuild of Christchurch and the surrounding areas following the earthquakes.
} 
brought into question. This is because the alcohol outlet data held by ARLA does not record whether licensed alcohol outlets are actively trading. As a result, although a large number of alcohol outlets in Christchurch were permanently closed as a result of the Canterbury Earthquakes, they were not recorded as closed by the ARLA until their license expired, which in many cases was years after the outlets were demolished and even replaced. As a result an alternative alcohol outlet database was built by contacting all liquor license holders recorded by ARLA as having operating alcohol outlets from 2009 to 2014. A team of ten computerassisted telephone interviewers using Voice Over Internet Protocol (VOIP) phones were used to collect current information on alcohol outlets in pre- and post-quake Christchurch. Information was obtained pertaining to the type of license (on- or off-site), opening and closing (either permanent or temporary) dates of their alcohol outlet/s as a result of the Canterbury Earthquakes as well as more general open ended information regarding the effects the earthquakes had on their alcohol trading businesses. The operating address of each outlet type both pre- and post-earthquake was obtained and geocoded and a rate per 1,000 population was calculated for each CAU for both time periods: pre-earthquake (December 2009) and post-earthquake (December 2014). This database is among the most accurate and spatially replete of its kind in New Zealand.

A continuous dependent variable was developed to measure the difference in the rates of on- and off-site alcohol outlets pre-and post-quake per CAU, by subtracting the 2014 rate from the 2009 rate. This yielded positive values for CAUs with increased post-quake rates, negative values for decreased rates and 0 values for neighbourhoods with no change. Alternative methods were considered in order to categorise neighbourhoods but the outlet data available to us was too sparse to conduct any form of time-series and/or trajectory analysis with statistical certainty, despite numerous attempts. 


\section{Independent variables}

A total of eight independent variables were used in the analysis. Data from Statistics New Zealand's census of 2013 was used to construct the first six variables thought to influence the spatial location choice of alcohol outlets based on previous local and international research (see Gorman \& Speer, 1997; Hay et al., 2009; Ellaway et al., 2010). These variables included the percent male, percent residents aged 15-29, percent resided for less than five years, percent foreign born, percent non-partnered, and the percent unemployed.

Two additional independent variables were also added. These included the percentage of the CAU that was red-zoned and the crime rate change per CAU. As previously discussed, the Residential Red Zone is a non-continuous area in Christchurch where earthquake damage was most severe, and where a substantial number of properties were deemed unsafe for future habitation. The Residential Red Zone is present in three primary areas, including a cluster of neighbourhoods to the north east of the CBD, the Port Hills (the most south eastern suburbs in Christchurch), and an area north of Christchurch. Damage to buildings and poor earthquake-induced living conditions in the Residential Red Zone resulted in a substantial population and business exodus in these areas, which has left much of these areas uninhabited. Neighbourhoods with a high percentage of land that is red-zoned are unsuitable for the re-location of any retail activity. Data for the calculation of the percentage of the CAU that is red-zoned (circa 2012) was obtained from CERA.

Lastly, in order to examine whether there is any association between the changing distribution of alcohol outlets and the changing distribution of crime in Christchurch, we added the crime rate change per CAU. Crime data for this factor was obtained from New Zealand Police's record of reported crime. Reported offences within Christchurch from $1^{\text {st }}$ January 2009 to $31^{\text {st }}$ December 2014 (six years) were obtained. Each offence contained a location (easting, northing), an estimated time of the offence as well as a description and 
classification. Similar to the calculation of the alcohol outlet change above, the six year study period was broken down into a pre-earthquake period $\left(1^{\text {st }}\right.$ January $2009-31^{\text {st }}$ December 2009) and a post-earthquake period ( $1^{\text {st }}$ January $2014-31^{\text {st }}$ December 2014$)$. The four year interim period was excluded in the analysis since this period covered the two major earthquake events in the sequence, separated by five months (i.e., September 2010 and February 2011) as well as a significant period of rebuilding. A total of 62,709 offences were reported to the Police across these two periods (pre-earthquake $=36,810$; post-earthquake $=$ 25,899). For each period the crime data was aggregated to the CAU-level and a mean annual crime rate per 1,000 population calculated. A continuous independent variable was then developed to measure the difference in the rates of crime pre-and post-quake per CAU, by subtracting the 2014 rate from the 2009 rate. This yielded positive values for CAUs with increased post-quake crime rates, negative values for decreased crime rates and 0 values for neighbourhoods with no change.

It is important to note that the calculation of the independent variables as well as the onand off-site alcohol outlet rates was done using sub-national population estimates calculated by Statistics New Zealand as the denominator rather than population data derived from the census alone. Understandably, there was considerable out- and intra-migration of residents in Christchurch following the earthquake which was difficult to monitor and resulted in much uncertainty regarding population numbers. To address this, Statistics New Zealand combined official census data with other available data (such as international travel documents and building consents) to produce three monthly population estimates at various levels of aggregation (Statistics New Zealand, 2011). These estimates were used where applicable to calculate certain variables. In general, population estimates remain consistently higher than the New Zealand census figures, taking into account the three month difference in observation, and census non-respondents. Likewise, the CAU boundaries across both periods 
were obtained from Statistics New Zealand who re-aligned the neighbourhood boundaries with updated census data in rare instances where the boundaries changed over the period of investigation (see Statistics New Zealand, 2013).

\section{Statistical analyses}

Initially, an ANOVA was run to compare the independent predictors by neighbourhood-level change in alcohol outlet rates. Next, spatial regression models were fitted to test the spatial association between the changes in on- and off-site alcohol outlet rates and the selected independent variables at the neighbourhood level. The use of other models such as an ordinary least squares is not applicable in this study as these types of models do not recognise that the influence of variables can change over space. Using the Lagrange Multiplier (LM) tests (LM-Error and LM-Lag), which tests the null hypothesis of no spatial dependence against alternatives of spatial error and spatial lag dependence respectively, we found strong evidence of spatial autocorrelation. Only the LM-Lag test statistic was significant, while the LM-Error statistic was not thereby motivating for the estimation of a spatial lag model. The general functional form of the spatial lag model is:

$$
y=p W y+X \mathrm{~B}+\varepsilon
$$

Where $y$ represents the change in on- or off-site alcohol outlet rates per 1,000 population, $W y$ is the weighted mean of the local values of $y$ in neighbouring areas, $p$ is the parameter, $X$ is the set of motivators, $\mathrm{B}$ is a vector of coefficients to be estimated and $\varepsilon$ is the error term. Spatial autocorrelation was modeled using second-order rook's contiguity.

One final concern in the modelling process is multicollinearity. Multicollinearity makes determining the importance of any given variable difficult because the effects of the variables are confounded due to possible correlations between them. Such a situation is only problematic if a high degree of multicollinearity is present among the variables of interest. 
This is not the case in the current analysis as bivariate correlations examined between the seven independent variables indicated only one relationship exceeding 0.80 , a common threshold of concern. All correlations are available to the interested reader. Analysis was performed using the GeoDa spatial statistical freeware package.

\section{Methodological limitations}

Before providing our results there are two main limitations in our method worth highlighting. First, we grouped on- and off-site alcohol outlets together in this study and did not disaggregate further (i.e., bars, restaurants, nightclubs). We are aware of the issues that arise when aggregating alcohol outlet data. These were recently highlighted by Gmel et al. (2016) whose particular concern is the fact that when studies aggregate different outlet types, a certain type of outlet (e.g., bar) can explain most of the aggregated (e.g. on-site license) effect found in subsequent analyses. While the 'devil may be in the detail' in our study too, we are in agreement with Morrison et al. (2016) who argues that while aggregation based studies may contain potential biases an aggregated and ecological approach to alcohol outlet studies still has merit. Particularly the fact that aggregation based studies are better able to identify significant effects in models as well as provide greater insight into an individuals' behaviour in their broader social and economic environment. Future research could certainly investigate how different types of on- and off-site alcohol outlets changed in the aftermath of the Canterbury Earthquakes, however, that was not our intention here.

Second, there are a number of other factors that are absent from these models that could possibly influence the spatial location of new alcohol outlets. These include factors such as the proximity to public transportation routes, building restrictions, land-use and zoning restrictions, traffic patterns and the location of existing entertainment establishments. However obtaining current data pertaining to the built environment in Christchurch at a CAU 
level of aggregation was problematic. This was mainly due to the vast number of demolitions and remediation work currently underway on commercial and residential properties; as well as on other infrastructures and utilities such as road, sewerage and power networks. Relying mainly on updated census information allowed us to focus on identifying the sociodemographic drivers of alcohol outlet change in post-earthquake Christchurch. As the rebuild of Christchurch continues, future research could aim to include a number of the omitted built and infrastructural factors listed above in statistical models in order to expand on the knowledge generated in this work.

\section{Results}

\section{Descriptive results}

Table 1 shows descriptive statistics of the rates of alcohol outlets per CAU pre- and postearthquake. Again, these figures indicate large variability in the rates of outlets between the two periods. Firstly, there has been a decline of 103 licensed alcohol outlets since the Canterbury Earthquakes (81 on-site; 22 off-site). Rates of on-site alcohol outlets in the preearthquake period range from zero to 385.23 outlets per 1,000 population whilst on-site outlets in the post-earthquake period range from zero to a more modest 139.72 outlets per 1,000 population. There is a similar trend in the rate of off-site outlets which declined from a rate of 59.88 to 25.95 outlets per 1,000 population pre- to post-earthquake. Across both periods and license types, the CAU which contained the highest rates of outlets was Cathedral Square located in the CBD. This is understandable as Cathedral Square was the location of a vast number of entertainment establishments in pre-quake Christchurch. Interestingly, only $24 \%$ of registered alcohol outlets that were open in the CBD before the earthquake, returned to the CBD after the cordon was lifted and were open post-earthquake (end 2014). The remaining alcohol outlets (76\%) either relocated permanently or closed 
down. The Moran's I for rates of alcohol outlets for both on and off-site licenses was higher post-earthquake, suggesting that alcohol outlets were more spatially clustered in the postearthquake period, in both instances significantly so.

Table 1: Descriptive statistics of neighbourhood level rates of alcohol outlets per 1,000 population pre- and post-earthquake

\begin{tabular}{ll|lllll}
\hline & $\mathrm{n}$ & Minimum & Maximum & Mean & SD & Moran's $I$ \\
\hline $\begin{array}{l}\text { Pre-earthquake } \\
\quad \text { On-site }\end{array}$ & 610 & 0 & 385.23 & 4.88 & 35.30 & 0.00 \\
$\quad 137$ & 0 & 59.88 & 0.81 & 5.48 & 0.00 \\
Off-site & & & & & \\
Post-earthquake & & & & & \\
$\quad$ On-site & 529 & 0 & 139.72 & 2.91 & 13.00 & 0.11 \\
$\quad$ Off-site & 115 & 0 & 25.95 & 0.54 & 2.41 & 0.10 \\
\hline
\end{tabular}

The rates of both on- and off-site alcohol outlets per CAU in Christchurch pre- and postearthquake are mapped in Figures 1 and 2. Unsurprisingly neighbourhoods with the highest rates of on-site alcohol outlets per 1,000 population pre-earthquake were located in the CBD of Christchurch and immediately surrounding neighbourhoods (see Figure 1). This spatial distribution has changed somewhat post-quake with on-site alcohol outlet rates generally increasing in neighbourhoods to the north and west of the CBD while decreasing in neighbourhoods in the CBD itself. A similar spatial change is evident when examining changes in rates of off-site alcohol outlets per 1,000 population with rates initially high in neighbourhoods within the $\mathrm{CBD}$ of the city pre-earthquake before spatially dispersing towards the northern regions of the city post-quake (see Figure 2). 



Figure 1: Spatial changes in on-site rates of alcohol outlets per 1,000 population pre- and post-earthquake 

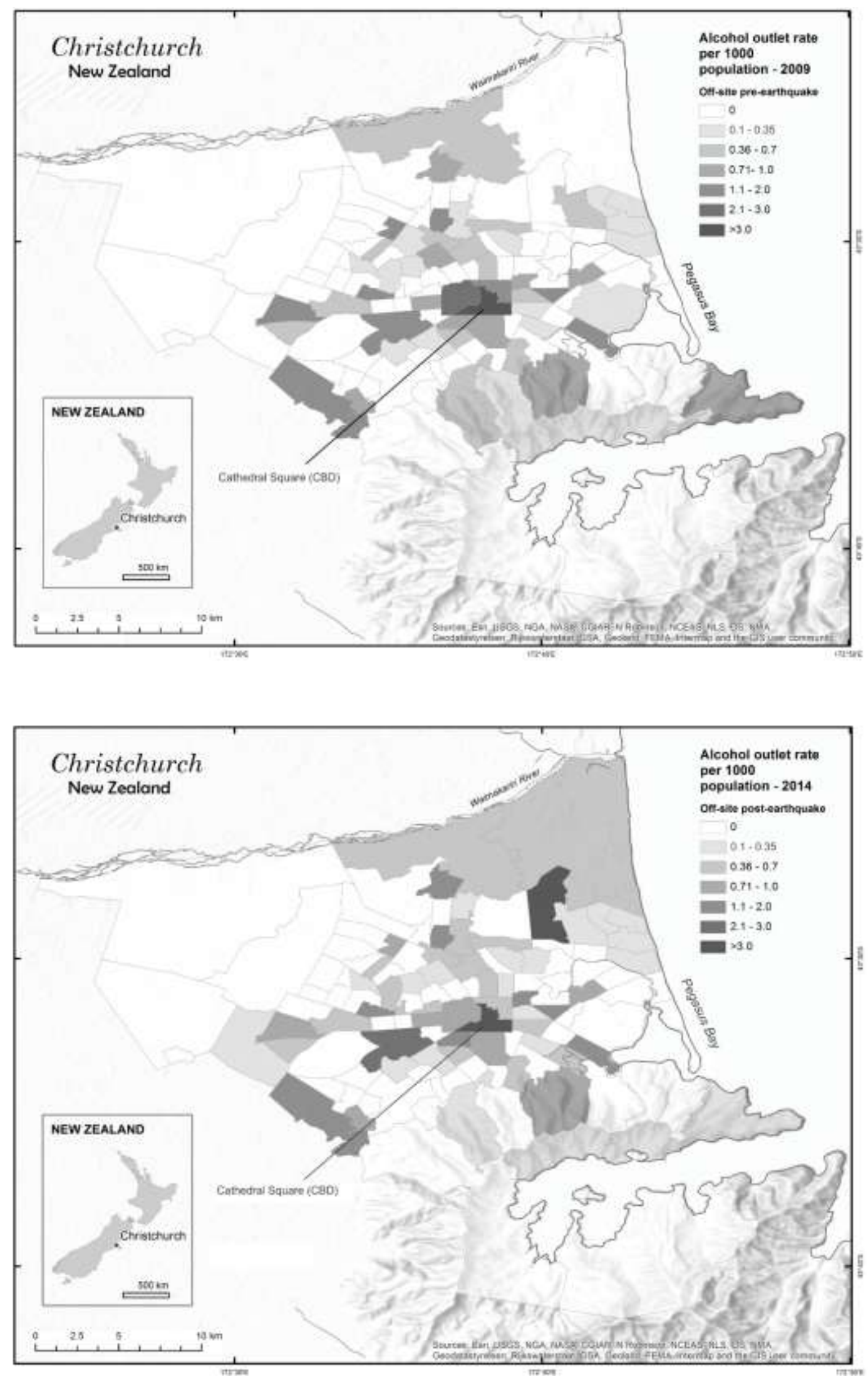

Figure 2: Spatial changes in off-site rates of alcohol outlets per 1,000 population pre- and post-earthquake 


\section{Analytical results}

Table 2 compares the neighbourhood-level predictors used in the study by on-site alcohol outlet change. Just under one third of neighbourhoods in Christchurch $(n=39)$ experienced an increase in rates of on-site alcohol outlets post-quake while $19 \%$ experienced a decrease ( $n$ $=23)$. Just under half of all neighbourhoods $(n=57)$ experienced no change in rates of onsite alcohol outlets per 1,000 population. Significant differences were found between four of the eight predictors by on-site alcohol outlet change with neighbourhoods that experienced an increase in rates of on-site alcohol outlets having a higher percentage of young, foreign born and single residents as well as having a higher percentage of residents who have resided in the neighbourhood for less than five years. Interestingly, no significant neighbourhood differences were found between on-site alcohol outlet change and the change in crime rates pre- and post-quake although all neighbourhoods experienced a mean decrease in crime rates per 1,000 population regardless of whether on-site alcohol outlet rates increased, decreased or stayed the same.

Table 3 contrasts the neighbourhood-level predictors used in the study by off-site alcohol outlet change. In contrast to the above, far fewer neighbourhoods experienced a change in rates of off-site alcohol outlets. Collectively only $27 \%$ of neighbourhoods $(n=32)$ experienced any change with the count equitably split between neighbourhoods that experienced an increase $(n=16)$ and decrease $(n=16)$ in off-site rates. Just under three quarters of neighbourhoods $(n=87)$ experienced no change. Neighbourhoods that experienced an increase in rates of off-site alcohol outlets had a significantly higher percentage of residents who resided in the neighbourhood for $<5$ years. Similar to the above, regardless of whether neighbourhoods experienced an increase, decrease or no change in off- 
Table 2: Neighbourhood characteristics for CAUs with increased, decreased or no change in on-site rates of alcohol outlets per 1,000 population

\begin{tabular}{|c|c|c|c|c|c|}
\hline Neighbourhood characteristics post-quake* & $\begin{array}{l}\text { Increased } \\
(n=39)\end{array}$ & $\begin{array}{l}\text { Decreased } \\
\quad(n=23)\end{array}$ & $\begin{array}{l}\text { No change } \\
\quad(n=57)\end{array}$ & $\mathrm{p}$-value $\dagger$ & $\begin{array}{c}\text { Total } \\
(n=119)\end{array}$ \\
\hline$\%$ male, mean $(\mathrm{sd})$ & $49.4(2.3)$ & $50.4(2)$ & $49.1(3.1)$ & 0.165 & $49.4(2.7)$ \\
\hline$\%$ aged $15-29$ years, mean (sd) & $24.5(10)$ & $21.2(10.1)$ & $18.7(4.7)$ & 0.002 & $21.1(8.3)$ \\
\hline$\%$ lived in neighbourhood <5 year, mean (sd) & $54.4(9.5)$ & $48.4(12.5)$ & $46.7(7.3)$ & 0.000 & $49.6(9.8)$ \\
\hline$\%$ foreign born residents, mean (sd) & $23.2(6)$ & $20.5(6.8)$ & $19.2(5.7)$ & 0.007 & $20.8(6.2)$ \\
\hline$\%$ unemployed, mean (sd) & $3.4(1.1)$ & $3.6(1.8)$ & $2.9(0.9)$ & 0.066 & $3.3(1.2)$ \\
\hline$\%$ single, mean $(\mathrm{sd})$ & $41.6(8.6)$ & $38.9(9.6)$ & $36.6(6.8)$ & 0.014 & $38.7(8.2)$ \\
\hline$\%$ red-zoned, mean $(\mathrm{sd})$ & $0.6(3.8)$ & $3.4(6.6)$ & $3.7(11.1)$ & 0.212 & $2.6(8.6)$ \\
\hline Crime rate change per 1,000 pop & $-14.3(27.8)$ & $-314.9(1243.2)$ & $-12.1(23.7)$ & 0.060 & $-71.4(550.5)$ \\
\hline
\end{tabular}

* Data obtained from the 2013 New Zealand census, CERA and New Zealand Police $\uparrow$ Calculated using ANOVA 
Table 3: Neighbourhood characteristics for CAUs with increased, decreased or no change in off-site rates of alcohol outlets per 1,000 population

\begin{tabular}{|c|c|c|c|c|c|}
\hline Neighbourhood characteristics post-quake* & $\begin{array}{l}\text { Increased } \\
(\mathrm{n}=16)\end{array}$ & $\begin{array}{l}\text { Decreased } \\
\quad(n=16)\end{array}$ & $\begin{array}{l}\text { No change } \\
\quad(\mathrm{n}=87)\end{array}$ & $\mathrm{p}$-value $\dagger$ & $\begin{array}{c}\text { Total } \\
(n=119)\end{array}$ \\
\hline$\%$ male, mean $(\mathrm{sd})$ & $49.9(1.8)$ & $50.3(2.4)$ & $49.2(2.8)$ & 0.239 & $49.4(2.7)$ \\
\hline$\%$ aged $15-29$ years, mean $(\mathrm{sd})$ & $21.9(6.7)$ & $24.8(11.6)$ & $20.2(7.7)$ & 0.113 & $21.1(8.3)$ \\
\hline$\%$ lived in neighbourhood <5 year, mean (sd) & $54.3(9.2)$ & $54.2(12.7)$ & $47.8(8.8)$ & 0.005 & $49.6(9.8)$ \\
\hline$\%$ foreign born residents, mean $(\mathrm{sd})$ & $20.3(5.8)$ & $23.8(6.5)$ & $20.3(6.2)$ & 0.105 & $20.8(6.2)$ \\
\hline$\%$ unemployed, mean (sd) & $3.4(1.2)$ & $3.5(1.7)$ & $3.2(1.1)$ & 0.540 & $3.3(1.2)$ \\
\hline$\%$ single, mean $(\mathrm{sd})$ & $39.8(6.9)$ & $41.7(10.5)$ & $37.9(7.9)$ & 0.197 & $38.7(8.2)$ \\
\hline$\%$ red-zoned, mean $(\mathrm{sd})$ & $1.6(5.9)$ & $0.6(1.2)$ & $3.2(9.7)$ & 0.487 & $2.6(8.6)$ \\
\hline Crime rate change per 1,000 pop & $-14.2(38.8)$ & $-432.7(1489.1)$ & $-15.4(25.9)$ & 0.017 & $-71.4(550.5)$ \\
\hline
\end{tabular}

* Data obtained from the 2013 New Zealand census, CERA and New Zealand Police $\uparrow$ Calculated using ANOVA 
site alcohol outlet rates, they all experienced a mean decrease in crime rate change; the difference also being significant.

Figure 3 shows the results of the spatial regression model examining the association between the change in on- and off-site alcohol outlet rates and the selected independent variables in the form of forest plots. Increases in rates of on-site alcohol outlets in neighbourhoods were positively associated with the percentage male, the percentage resided in the neighbourhood for $<5$ years and the crime rate change, while a significant and negative association was found with percentage population aged between 15 and 29 years.

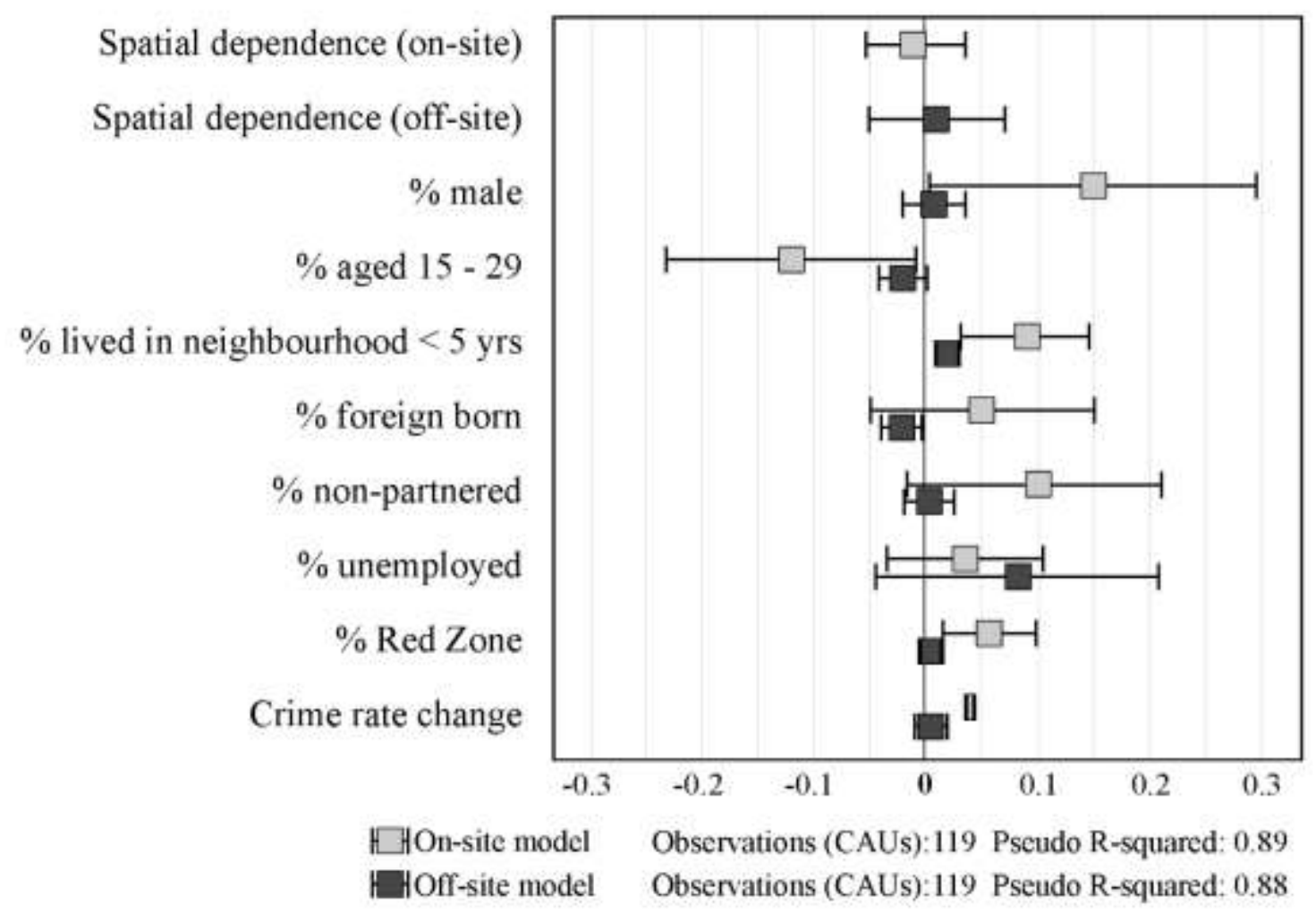

Figure 3: Spatial regression results for predicting changes in on- and off-site rates of alcohol outlets per 1,000 population pre- and post-earthquake 
Similar to the on-site outlet results, positive associations were found between off-site alcohol outlet rate changes and the percentage resided in the neighbourhood for less than five years and the crime rate change while negative associations were found with percentage aged between 15 and 29 years and the percentage foreign born. Overall, both models performed very well, with 88 and 89 percent of the variation of the changing rates of on- and off-site alcohol outlets rates being explained by the selected independent variables.

\section{Discussion}

The effects of alcohol availability and access upon patterns of consumption have been extensively studied with researchers showing that greater availability of, and access to, alcohol generally leads to increased consumption (see Truong \& Sturm, 2007; Ayuka et al., 2014). Studies have also shown that populations in post-disaster cities typically increase their alcohol consumption (see Schroeder \& Polusny, 2004) which makes examining the changing spatial distribution of alcohol outlets in a post-disaster city an important topic for investigation in disaster-related urban research. Not without limitations, we have begun to examine this phenomena and have made a number of important preliminary findings. First, and most obvious, is the fact that alcohol outlets - like most other retail businesses experience significant upheaval in the aftermath of a natural disaster. Outlets close down (temporarily or permanently), change location, and according to our evidence, increasingly cluster together. Of the 747 alcohol outlets operating in Christchurch before the earthquake only $56 \%$ were operating by the end of 2014; many closed down permanently; and others relocated. Second, our findings suggest that changes in the rates of on- and off-site alcohol outlets in neighbourhoods are not random but are, in part, related to the socio-demographic composition of neighbourhoods. Alcohol outlet rates were found to increase in more residentially unstable neighbourhoods and in neighbourhoods with a lower percentage of 
residents aged 15 to 29 . Finally, rates of both on- and off-site alcohol outlets also significantly increased in neighbourhoods with a greater crime rate change. This latter finding provides the first empirical clue of a spatial association between changing alcohol outlet distributions and urban crime in a post-disaster setting.

From a purely demographic perspective the fact that an increase in alcohol outlets was not found to be statistically associated with neighbourhoods where there are young and unemployed people supports the notion that older, more established neighbourhoods are favoured by business owners investigating suitable locations for new outlets. On-site alcohol outlets also increased in neighbourhoods with a higher percentage of males possibly indicating a geographic targeting of this particular gender. Among drinkers in New Zealand, men are more likely to drink daily or several times a week, drink heavily on a single occasion and drink heavily more often (Ministry of Health, 2009). Previous research has shown that while there is generally a socio-economic gradient in alcohol provision - with greater densities of outlets in more deprived areas (Gorman \& Speer, 1997; Pearce et al., 2008) - this variation is not systematic (Ellaway et al., 2010) and other local contextual factors may also have a role to play in outlet location choice. Given the dynamism of the rebuilt process currently underway in Christchurch it is possible that additional yet unknown factors are also influencing the location of new outlets. Finally, the same socio-demographic factors were found to impact the changing rates of both on- and off-site alcohol outlets, while both models performed almost identically. This is most likely a consequence of the similar spatial distribution (and redistribution) of both on- and off-site outlets across both periods or it could simply be that the redistribution of outlets in a post-disaster setting is governed more by availability and associated socio-demographics than by the type of outlet. 


\section{Practical and policy implications}

So what are the likely practical implications of a neighbourhood-level spatial change in alcohol outlet density on alcohol related harm? Previous research has examined this phenomena mostly in the context of changing alcohol legislation and/or regulation, particularly in the United States. Conrow et al. (2015) for example found that changes in the alcohol outlet environment (i.e., bars that received a liquor license) in Atlanta were related to an increase in the occurrence of crime events in the city while across California Gruenewald and Remer (2006) found that an increase in alcohol outlets accelerated violent crime rates particularly in impoverished neighbourhoods, and in neighbourhoods with greater income inequality. In Melbourne, Australia, Livingston (2008) found that changes in the number of alcohol outlets were directly associated with the amount of violence a community experienced although this relationship was found to vary by type of neighbourhood as well as the type of outlet. In our study we found a direct relationship between rates of both on- and off-site alcohol outlets and crime rate change. That is, the higher the change in alcohol outlet rates in neighbourhoods, the higher the crime rate change. Recent research by Breetzke et al (in press) has shown how crime in Christchurch has spatially diffused away from the CBD and into nearby neighbourhoods on the periphery of the central city. Whilst crime overall has declined in Christchurch post-quake the authors also found that domestic violence had in fact increased post-disaster and attributed this increase to the increased spatial clustering of alcohol outlets as well as the nature of domestic violence in the city. Our aggregated crime results did not allow us to infer to this level of detail but do show how changing rates of both on- and off-site alcohol outlets in neighbourhoods can be considered an environmental risk factor for crime and potentially for excessive alcohol consumption, the latter typically being a precursor to violence (see Zhang et al., 2015). 
In a similar vein it is likely then that neighbourhoods in Christchurch that experienced a decrease in rates of on- and off-site alcohol outlets would most likely experience a decrease in alcohol-related harms. There is some evidence to support this as while crime has decreased overall in Christchurch post-quake (see Breetzke et al., in press), we found that the decrease in rates of crime was greater in neighbourhoods that experienced an associated decrease in both on- and off-site alcohol outlets (see Tables 2 and 3). Neighbourhoods that experienced an increase in rates of alcohol outlets did also experience decreased crime rates, but at a lower magnitude than other neighbourhoods. A study by Zhang et al. (2015) in Atlanta has found that a reduction in alcohol outlet density in neighbourhoods with high density of alcohol outlets substantially reduced exposure to violent crime in affected neighbourhoods. It could be that in a post-disaster setting the same results hold true.

From a purely public health perspective, Johnson et al. (2009) found that a changes in off-premise outlet densities were directly related to attempted and completed suicide rates while Cohen et al. (2006) found that a reduction in alcohol availability within neighbourhoods was associated with a significant reduction in gonococcal infection rates, although this association was partially mediated by neighbourhood social capital. Much less is known however about the effects on a changing urban alcohol environment in urban New Zealand but based on the wealth of evidence provided by international scholars it is reasonable to assume that similar adverse outcomes are likely particularly for neighbourhoods that have experienced an increase in rates of alcohol outlets in Christchurch. Of greater concern however is the fact that the increase in alcohol outlets in certain neighbourhoods of the city is occurring in a post-disaster setting where residents are increasingly under strain. According to Renoef (2012) this strain and its psychological effects are likely to accumulate rather than lessen over time while previous research has found that the effects of delayed stress can significantly increase voluntary consumption among 
vulnerable persons (see Steptoe et al., 1996; Magrys \& Olmstead, 2015) which suggests that the full effects of the spatial redistribution of alcohol outlets in Christchurch on residents' health and wellbeing are yet to be felt.

Finally, one important contribution of this study relates to the implications for local policy makers as they provide support for measures that limit the number of alcohol outlet licenses within new (or rebuilt) urban areas. The most relevant policy document in this regard is the Sale and Supply of Alcohol Act 2012 (SSAA). The SSAA was passed in 2012 but only came into effect in 2014 and was implemented to reduce alcohol-related harm by among other things, restricting access to, and availability of, alcohol particularly in at-risk communities. Rather paradoxically the SSAA does not permit a license to be declined on the basis of the number of existing outlets in an area but does allow councils in New Zealand to develop their own local alcohol plans (LAPs) to manage and govern the sale and supply of alcohol. Whilst there is provision in each LAP for local authorities to 'limit the location and density of licenses' the existing alcohol outlet density in an area is not taken into account in its criteria and as a result there are numerous clusters of high outlet areas both across the rebuilt Christchurch and across the country as a whole (New Zealand Law Commission, 2009). In a post-disaster setting, applications for new alcohol outlet licenses need even greater scrutiny and additional criteria - not currently included in legislation - need to be applied such as the location of existing outlets and proximity to vulnerable populations. Indeed, research is beginning to emanate showing significant increases in alcohol consumption since the Canterbury Earthquakes with males in particular reporting significantly higher levels of alcohol consumption than females (see Marie, 2015). No association was, however, found between traumatic exposure severity and alcohol consumption with consumption increasing among participants in the study regardless of their exposure to the trauma of the Earthquakes. Of course, the increase in alcohol consumption 
among individuals may not be specifically related to the increase in alcohol outlets in their own neighbourhood but a global spatial association was found in our study with changing alcohol rates and certain neighbourhood characteristics.

The increase in crime and hazardous drinking in neighbourhoods in post-quake Christchurch (see Ensor, 2013; Breetzke et al., in press) has already led the Christchurch City Council (CCC) to place a number of temporary alcohol bans on these neighbourhoods (CCC, 2015). The majority of these neighbourhoods including Riccarton, Papanui, Merivale and Addington lie adjacent to the $\mathrm{CBD}$ and have seen an increase in violence and disorder since the Canterbury Earthquakes as people increasingly consume alcohol in suburban areas after the closure of many hospitality and entertainment venues in the central city. This measure is applaudable but reactive and suggests a growing acknowledgement among authorities of the issues that are likely to emanate from a policy that does not take into cognisance the underlying social and built environment of new license locations. While the SSAA does allow for objections to be made for new alcohol license applications, no criteria exists which allows for objections to be made based on the likely consequences that additional licensed outlets are will have on existing communities in terms of crime and/or health. Whilst this may be overtly regulatory the unintended and/or consequential effects of increased neighbourhood-level access and availability of alcohol in a post-disaster setting cannot be overemphasised.

In summary, the results of this study pose an important question: Do post-disaster (re)built urban environments support the health and well-being of affected residents? Given the notable increase in disaster events affecting urban areas across the world, this is an important avenue for future research. Studies examining the changes in alcohol accessibility - however measured - are in their infancy. Knowing what determines these changes and the impact that these changes will have on affected residents in a post-disaster setting is 
important from a variety of perspectives. We believe that in doing this research we have made a small but important contribution in this regard and provide an important spatial platform for future research of this nature.

\section{References}

Ayuka, F., Barnett, R., Pearce, J. (2014). Neighbourhood availability of alcohol outlets and hazardous alcohol consumption in New Zealand, Health and Place, 29, pp. 186-199.

Bluthenthal, R. N., Choen. D. A., Farley, T. A., Scribner, R., Beighley, C., Schonlau, M. \& Robinson, P. L. (2008) Alcohol availability and neighborhood characteristics in Los Angeles, California and southern Louisiana, Journal of Urban Health, 85(2), pp. 191-205.

Breetzke, G. D., King, M. \& Fabris-Rotelli, I. (in press) The impact of the Canterbury Earthquakes on crime in Christchurch, New Zealand. Australian and New Zealand Journal of Criminology.

Burke, Jr., J. D., Borus, J. F., Burns, B. J., Millstein, K. H. \& Beasley, M.C. (1982) Changes in children's behavior after a natural disaster, American Journal of Psychiatry, 139(8), pp. $1010-1014$

Cameron, M. P., Cochrane, W., McNeill, K., Melbourne, P., Morrison, S. L. \& Robertson, N. (2012) The impacts of liquor outlets in Manukau City summary report - revised (Wellington: Alcohol Advisory Council of New Zealand). 
Cameron, L. \& Shah, M. (2015) Risk-taking behavior in the wake of natural disasters, Journal of Human Resources, 50(2), pp. 484-515.

Cameron, M. P., Cochrane, W., Gordon, C. \& Livingston, M. (2016) Alcohol outlet density and violence: A geographically weighted regression approach, Drug and Alcohol Review, 35, pp. 280-288.

Canterbury Earthquake Recovery Authority (CERA). (2015) Demolitions, Available at http://cera.govt.nz/demolitions/list (accessed 2 October 2016).

Christchurch City Council (CCC). (2015) Alcohol bans, Available at http://www.ccc.govt.nz/consents-and-licenses/business-licenses-andconsents/alcohol/alcohol-bans (accessed 25 January 2017).

Cohen, D. A., Ghosh-Dastidar, B., Scribner, R., Miu, A., Scott, M., Robinson, P., Farley, T. A., Bluthenthal, R. N. \& Brown-Taylor, D. (2006) Alcohol outlets, gonorrhoea, and the Los Angeles civil unrest: a longitudinal analysis, Social Science \& Medicine, 62(12), pp. 30623071.

Conrow, L., Aldstadt, J. \& Mendoza, N. S. (2015) A spatio-temporal analysis of on-premises alcohol outlets and violent crime events in Buffalo, NY, Applied Geography, 58, pp. 198-205.

Ellaway, A., Macdonald, L., Forsyth, A. \& Macintyre, S. (2010) The socio-spatial distribution of alcohol outlets in Glasgow city, Health \& Place, 16(1), pp. 167-172. 
Ensor, B. (2013) Quake Changes Christchurch Crime Patterns. Available at http://www.stuff.co.nz/national/christchurch-earthquake/8723395/Quake-changesChristchurch-crime-patterns (accessed 25 January 2017).

Escobedo, L. G. \& Ortiz, M. (2002) The relationship between liquor outlet density and injury and violence in New Mexico, Accident Analysis \& Prevention, 34, pp. 689-694.

Gmel, G., Holmes, J. \& Studer, J. (2016) Are alcohol outlet densities strongly associated with alcohol-related outcomes? A critical review of recent evidence, Drug and Alcohol Review, 35 , pp. $40-54$.

Gorman, D. M. \& Speer, P. M. (1997) The concentration of liquor outlets in an economically disadvantaged city in the northeastern United States, Substance Use \& Misuse, 32(14), pp. 2033-46.

Gorman, D. M., Speer, P. W., Gruenewald, P. J. \& Labouvie, E. W. (2001) Spatial dynamics of alcohol availability, neighborhood structure and violent crime, Journal of Studies on Alcohol, 62(5), pp. 628-636.

Gruenewald, P. J. \& Remer, L. (2006) Changes in outlet densities affect violence rates, Alcoholism: Clinical and Experimental Research, 30(7), pp. 1184-1193.

Han, D. \& Gorman, D. M. (2013) Exploring spatial associations between on-sale alcohol availability, neighborhood population characteristics, and violent crime in a geographically isolated city, Journal of Addiction, Article ID 356152, DOI: 10.1155/2013/356152. 
Hay, G. C., Whigham, P. A., Kypri, K. \& Langley, J. D. (2009) Neighbourhood deprivation and access to alcohol outlets: a national study, Health \& Place, 15(4), pp. 1086-1093.

Johnson, F. W., Gruenewald, P. J. \& Remer, L. G. (2009) Suicide and alcohol: do outlets play a role? Alcoholism: Clinical and Experimental Research, 33(12), pp. 2124-2133.

Johnson, L. A. \& Mamula-Seadon, L. (2014) Transforming governance: how national policies and organizations for managing disaster recovery evolved following the 4 September 2010 and 22 February 2011 Canterbury Earthquakes, Earthquake Spectra, 30(1), pp. 577-605.

Kam, W. Y., Pampanin, S. \& Elwood, K. J. (2011) Seismic performance of reinforced concrete buildings in the 22 February Christchurch earthquake, Earthquake Bulletin of New Zealand Society of Earthquake Engineers, 44, pp. 239-278.

LaVeist, T. A. \& Wallace, J. M. (2000) Health risk and inequitable distribution of liquor stores in African American neighborhood, Social Science \& Medicine, 51(4), pp. 613617.

Livingston, M. (2008). A longitudinal analysis of alcohol outlet density and assault, Alcoholism: Clinical and Experimental Research, 32(6), pp. 1074-1079.

Magrys, S. A. \& Olmstead, M. C. (2015) Acute stress increases voluntary consumption of alcohol in undergraduates, Alcohol \& Alcoholism, 50(2), pp. 213-218. 
Marie, L. M. A. (2015) The effect of the Canterbury earthquakes on alcohol consumption and motivations for drinking among psychologically resilient individuals. Unpublished Master's thesis, Department of Psychology, University of Canterbury, Christchurch, New Zealand.

Mearidy-Bell, L. (2013) Adolescent victims of natural disasters: a phenomenological study of health on lived experiences and behaviors displayed after a crisis, Journal of Human Behavior in the Social Environment, 23(4), pp. 536-551.

Ministry of Health. (2009). Alcohol use in New Zealand: Key results of the 2007/08 New Zealand Alcohol and Drug Use Survey. (Wellington: Ministry of Health).

Morrison, C., Cerda, M., Gorman, D. M., Gruenewald, P. J., Mair, C. F., Naimi, T. S., Scribner, R., Stockwell, T., Toomey, T. L. \& Wieczorek, W. F. (2016) Commentary on Gmel et al. (2015): are alcohol outlet densities strongly associated with alcohol-related outcomes? a critical review of recent evidence, Drug and Alcohol Review, 35, pp. 55-57.

New Zealand Law Commission. (2009) Alcohol in our Lives: An Isues Paper on the Reform of New Zealand's Liquor Laws. Available at http://www.lawcom.govt.nz/ProjectIssuesPaper.aspx?ProjectID=154 (accessed 30 January 2017).

New Zealand Treasury. (2013) Budget policy statement (Wellington: New Zealand Government). 
Parker, M. \& Steenkamp, D. (2012). The economic impact of the Canterbury Earthquakes, Reserve Bank of New Zealand, Available at http://www.rbnz.govt.nz/research_and_publications/reserve_bank_bulletin/2012/2012sep75_ 3parkersteenkamp.pdf (accessed 26 January 2017).

Pearce, J., Day, P. \& Witten, K. (2008) Neighbourhood provision of food and alcohol retailing and social deprivation in urban New Zealand, Urban Policy and Research, 26(2), pp. 213-227.

Renoef, C. A. (2012) Do the psychological effects of ongoing adversity in a natural context accumulate or lessen over time? The case of the Canterbury Earthquakes, Unpublished Master's degree, Department of Psychology, University of Canterbury, Christchurch, New Zealand.

Rohrbach, L. A., Grana, R., Vernberg, E., Sussman, S. \& Sun, P. (2009) Impact of Hurricane Rita on adolescent substance abuse, Psychiatry, 72(3), pp. 222-237.

Schneider, S. \& Gruber, J. (2013) Neighbourhood deprivation and outlet density for tobacco, alcohol and fast food: first hints of obesogenic and addictive environments in Germany, Public Health Nutrition, 16(7), pp. 1168-1177.

Schroeder, J. \& Polusny, M. (2004) Risk factors for adolescent alcohol use following a natural disaster, Prehospital and Disaster Medicine, 19(1), pp. 122-127. 
Statistics New Zealand. (2011). Estimating local populations after the 2010/11 Canterbury earthquakes. Available from

http://www.stats.govt.nz/browse_for_stats/population/estimates_and_projections/estimatingpop-after-chch-quakes-paper.aspx (accessed 30 January 2017).

Statistics New Zealand. (2013). 2013 Census meshblock dataset. Available from http://www.stats.govt.nz/Census/2013-census/data-tables/meshblock-dataset.aspx (accessed 15 February 2017).

Steptoe, A., Wardle, J., Pollard, T. M., Canaan, L. \& Davies, G. J. (1996) Stress, social support and health-related behavior: a study of smoking, alcohol consumption and physical exercise, Journal of Psychosomatic Research, 41(2), pp. 171-180.

Stevenson, J., Vargo, J., Seville, E., Kachali, H., McNaughton, A. \& Powell, F. (2012) The recovery of Canterbury's organisations: a comparative analysis of the 4 September 2010, 22 February and 13 June 2011 Earthquakes, Resilient Organisations research report 2011/04.

Stockwell, T., Zhao, J., Macdonald, S., Pakula, B., Gruenewald, P. \& Holder, H. (2009) Changes in per capita alcohol sales during the partial privatization of British Columbia's retail alcohol monopoly 2003-2008: a multi-level local area analysis, Addiction, 104(11), pp. $1827-1836$.

Treno, A. J., Johnson, F. W., Remer, L. G. \& Gruenewald, P. J. (2011) The impact of outlet densities on alcohol-related crashes: a spatial panel approach, Accident: Analysis and Prevention, 39(5), pp. 894-901. 
Truong, K. \& Sturm, R. (2007) Alcohol outlets and problem drinking among adults in California, Journal of Studies on Alcohol and Drugs, 68(6), pp. 923-933.

Ursano, R. J., Fullerton, C. S. \& Benedek, D. M. (2009) What is psychopathology after disasters? Considerations about the nature of the psychological and behavioral consequences of disasters, in: S. Galea \& F. H. Norris (Eds) Mental Health and Disasters, pp. 131-142. (Cambridge: Cambridge University Press).

Vinther-Larsen, M., Huckle, T., You, R. \& Casswell, S. (2013) Area level deprivation and drinking patterns among adolescents, Health \& Place, 19(1), pp. 53-58.

Zhang, X., Hatcher, B., Clarkson, L., Holt, J., Bagchi, S., Kanny, D. \& Brewer, R. D. (2015) Changes in density of on-premises alcohol outlets and impact on violent crime, Atlanta, Georgia, 1997-2007, Preventing Chronic Disease, 12, pp. 1-10. 